\title{
Abnormalities of the Corpus Callosum
}

\author{
${ }^{1}$ Sonila Pashaj, ${ }^{2}$ Eberhard Merz
}

\begin{abstract}
Presence or absence of the fetal corpus callosum plays an important role in prenatal counselling. With the recent development of 3D ultrasound technology, it is not only possible to demonstrate the corpus callosum precisely in the median plane but also to perform measurements of its different anatomical parts. This permits the diagnosis of hypoplasia and hyperplasia of the corpus callosum. Three-dimensional ultrasound enables even the unexperienced sonographer to take volumes of the fetal brain. Showing these volumes to experts in the field of neurosonography, corpus callosum pathologies can be detected via virtual examinations. Regarding all corpus callosum anomalies, hypo- and hyperplasia are the less reported corpus callosum abnormalities in the literature. Further investigations are necessary to predict the outcome of fetuses with corpus callosum pathologies.
\end{abstract}

Keywords: Agenesis, Corpus callosum, Fetus, Hyperplasia, Hypoplasia, Malformation, Partial agenesis, Ultrasound.

How to cite this article: Pashaj S, Merz E. Abnormalities of the Corpus Callosum. Donald School J Ultrasound Obstet Gynecol 2017;11(4):288-293.

\section{Source of support: Nil}

Conflict of interest: None

\section{INTRODUCTION}

The brain's complexity arises from its connectivity. ${ }^{1}$ The largest connective pathway of the human brain is the corpus callosum. It is made of over 190 million nerve fibers that connect the left and right hemispheres of the brain. ${ }^{2}$ Each hemisphere of the brain is specialized in controlling movement and feeling in the opposite half of the body, as well as in processing certain types of information (such as language or spatial patterns). Thus, to coordinate movement or to process complex information, the hemispheres must communicate with each other.

The function of the corpus callosum in humans was first investigated in "split-brain" patients whose callosum was severed surgically for the treatment of epilepsy. ${ }^{3,4}$ There is, nevertheless, another population that provides

\footnotetext{
${ }^{1}$ Consultant, ${ }^{2}$ Professor

${ }^{1,2}$ Center for Ultrasound and Prenatal Medicine, Krankenhaus Nordwest, Frankfurt am Main, Hessia, Germany

Corresponding Author: Sonila Pashaj, Consultant, Center for Ultrasound and Prenatal Medicine, Krankenhaus Nordwest Frankfurt am Main, Germany, e-mail: sonila_pashaj@hotmail. com
}

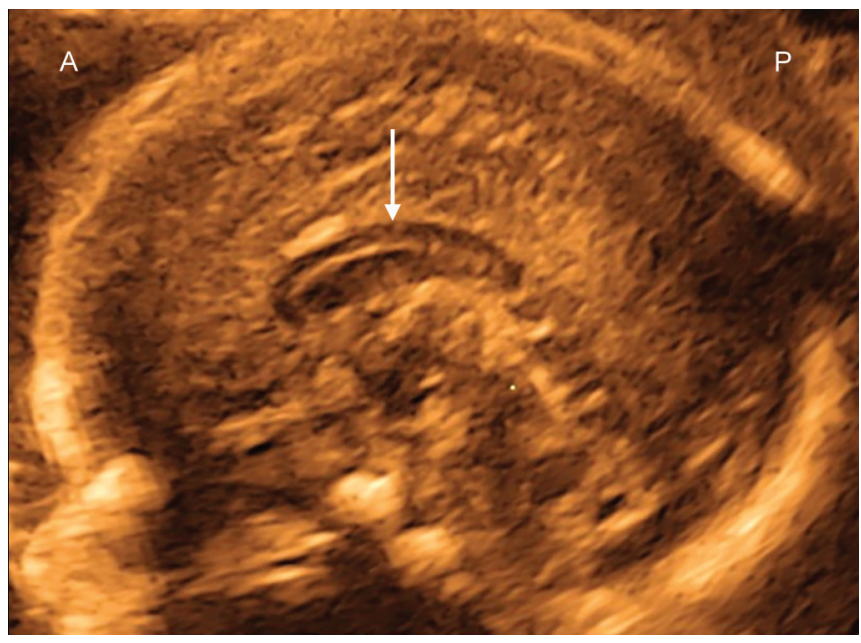

Fig. 1: Surface-rendered image of a corpus callosum $(\rightarrow)$ at 19 weeks' gestation (median plane). A: Anterior; P: Posterior

more information about the function of the corpus callosum and the role of altered connectivity in neurodevelopmental disorders: Individuals with agenesis of the corpus callosum (ACC). ${ }^{5}$

The prenatal sonographic demonstration of the fully expressed corpus callosum with "rostrum, genu, body and splenium" is possible starting from 18 to 19 weeks of gestation (Fig. 1). However, abnormalities of the corpus callosum cannot be diagnosed exactly before 20 weeks' gestation. The sonographically detectable abnormalities of the corpus callosum include six different pathologies related to the structure of the corpus callosum: Complete agenesis, partial agenesis, hypoplasia, hyperplasia, combination of hypo- and hyperplasia, and lipoma with abnormally high echogenicity. ${ }^{6}$

\section{PREVALENCE OF CORPUS CALLOSUM MALFORMATIONS}

The true prevalence and the clinical significance of abnormalities of the corpus callosum continue to be controversially discussed, depending on the characteristics of the populations selected for the study and the method of ascertainment. Freytag et $\mathrm{al}^{7}$ reported a prevalence rate of 0.3 to $0.7 \%$ in the general population. In a series of unselected autopsies, the postnatal prevalence of callosal anomalies was found to be 0.5 per 10,000 children. ${ }^{8}$ The ACC was identified in $3 \%$ of fetuses with ventriculomegaly, ${ }^{9}$ while ventriculomegaly was mild in approximately $10 \%$ of these fetuses. ${ }^{10}$ A higher prevalence is reported in children with neurodevelopment disability or 
a suspected neurogenetic condition. Jeret et $\mathrm{al}^{11}$ reported 33 cases of ACC in 1,447 computerized tomographies of developmentally disabled individuals and calculated a prevalence of $2.3 \%$. Wang et $\mathrm{al}^{12}$ published an article on the prevalence of congenital brain anomalies. The authors examined 2,309 clinically normal term neonates within 3 days of birth and reported a prevalence of ACC in this population of $1: 1000 .^{13}$ In a paper published in 2008, Glass et $\mathrm{al}^{13}$ described the epidemiology, risk factors, and accompanying malformations seen in patients with ACC, using a large population-based database of all malformations diagnosed in the first year of life in California from 1983 to 2003 . The combined prevalence of ACC (agenesis) and HCC (hypoplasia) ranged at 1.8 per 10.000 live births. ${ }^{13}$

\section{INDICATIONS FOR DISPLAYING THE CORPUS CALLOSUM}

Demonstration of the corpus callosum anatomy as an important landmark for brain development is only performed in cases of fetal or maternal indications and suspected familial disorders ${ }^{14}$ (Table 1 ).

\section{SONOGRAPHIC DEMONSTRATION OF CORPUS CALLOSUM ABNORMALITIES}

Three-dimensional (3D) ultrasound enables a better spatial orientation and precise control of the orthogonal two-dimensional (2D) planes in the examination of the fetus. ${ }^{15-19}$ The 3D neurosonography performed transabdominally or transvaginally further facilitates the exact demonstration of the corpus callosum, allowing to introduce the procedure as an integral part of the routine anatomical ultrasound examination. ${ }^{20,21}$

Table 1 Indications for examination of the fetal corpus callosum ${ }^{14}$

a. Fetal indications
Dilatation of the lateral ventricles
Absence of the cavum septi pellucidi, and widely separated
parallel frontal horns
Abnormal head circumference
Fetal brain or spinal masses
Twin pregnancy
Fetuses presenting with extracerebral multiple malformations that
can be associated with brain lesions, e.g., thoracic lymphangioma
and megalencephaly, cardiac malformation, and leukomalacia
b. Maternal indications
Infections
Coagulation disorders
Metabolic disorders
c. Suspected familial disorders
X-linked hydrocephalus
Tuberous sclerosis
Neurofibromatosis type I

Direct signs of corpus callosum abnormalities are detected in the median plane of the brain. The indirect signs of corpus callosum pathologies such as absence of cavum septi pellucidi or ventriculomegaly are seen in the axial planes of the brain. However, these indirect signs are not always present at the time of the first malformation scan and may become apparent only in the late second or third trimester.

\section{AGENESIS OF THE CORPUS CALLOSUM}

Prenatal diagnosis of ACC in 2D ultrasound was first described by Comstock et al. ${ }^{10}$ A definitive diagnosis of ACC relies on the identification of the direct and/or indirect signs. ${ }^{22-24}$ Direct signs consist of the demonstration of the absence of the CC in the median (= mid-sagittal) as well as in the coronal planes of the fetal brain (Figs 2 and 3). The midsagittal plane shows an absent corpus callosum and an atypical radial appearance of the median sulci, which are directed toward the third ventricle (Fig. 2). Indirect signs include the so-called "tear drop"-shaped lateral ventricle ${ }^{25}$ or colpocephaly ${ }^{9}$ (Fig. 4), which represent focal dilatations of the atria and occipital horns of the lateral ventricles. Generally, no cingulate gyrus is visualized or it may appear only incompletely. ${ }^{23}$ Other potential sonographic findings in the coronal and axial planes include a high-riding third ventricle between widely separated parallel lateral ventricles, several subtypes of interhemispheric cysts, not all of which communicate with the ventricles, and an abnormal course of the pericallosal artery. ${ }^{23}$

\section{PARTIAL ACC}

Partial ACC is diagnosed when at least one of the anatomical segments is missing, while the height is within

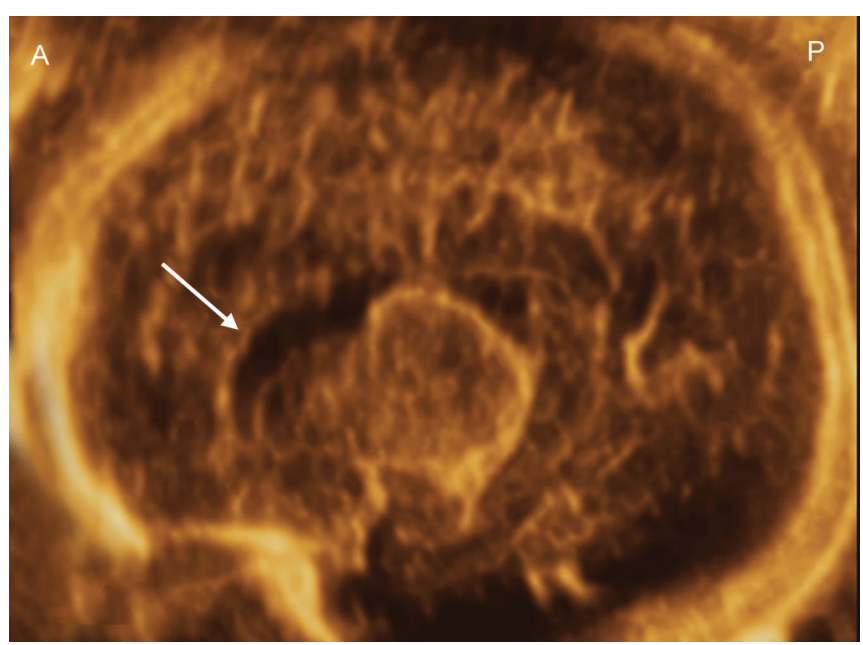

Fig. 2: Agenesis of the corpus callosum $(\rightarrow)$ at 38 weeks of gestation. Surface-rendered image of the median cut plane. The median sulci show an atypical radial appearance. A: Anterior; P: Posterior 


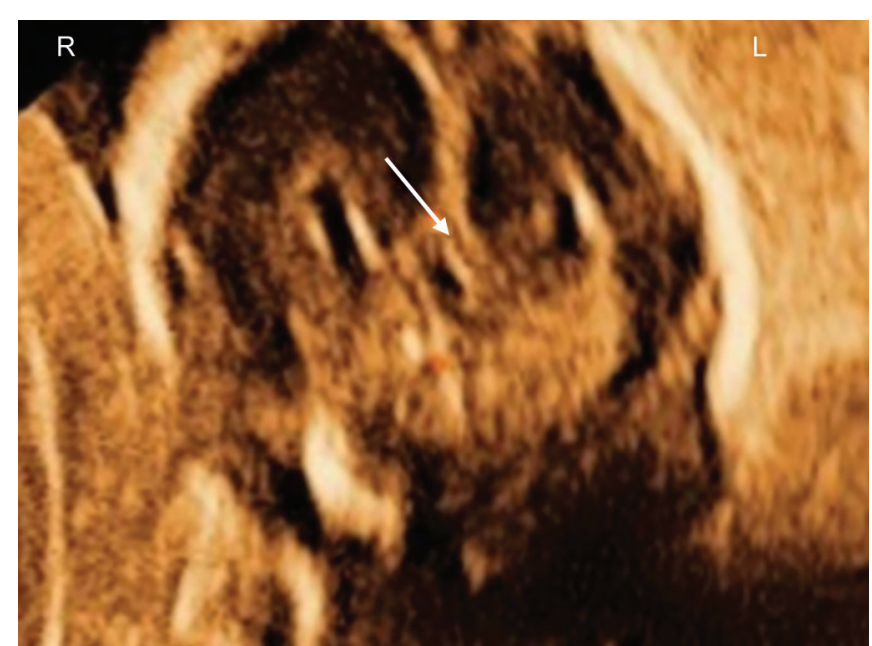

Fig. 3: Agenesis of the corpus callosum $(\rightarrow)$ at 21 weeks of gestation. Coronal surface view. There is no connection between the two brain hemispheres. R: Right; L: Left

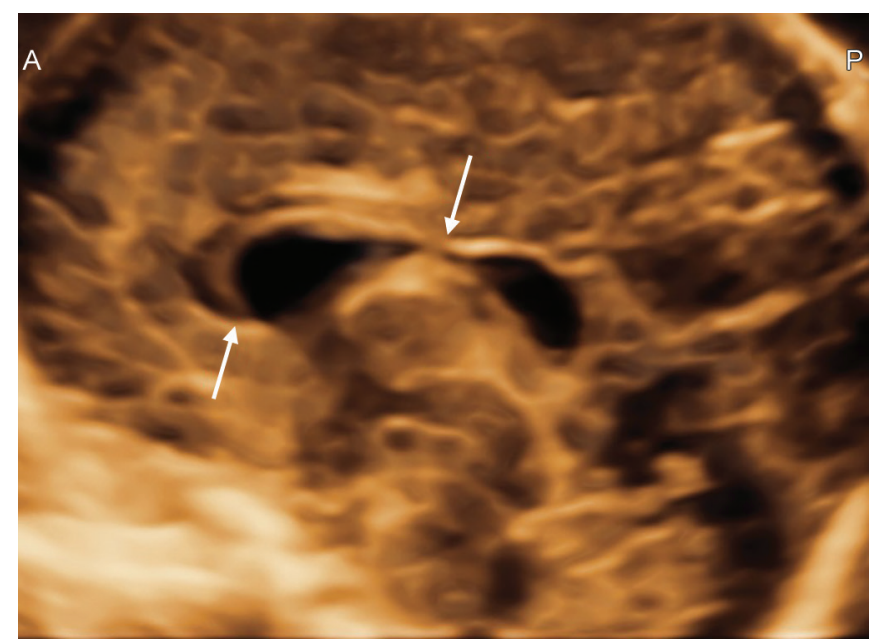

Fig. 5: Partial ACC (surface view) at 24 weeks' gestation. The picture shows the corpus callosum only on the front side $(\rightarrow \leftarrow)$, while the posterior part is missing. A: Anterior; $P$ : Posterior

the normal range, and all three lengths of the corpus callosum are below the 5 th percentile of normal growth charts $^{6}$ (Fig. 5).

Indirect signs similar to those observed in ACC may be present or absent. The most important sign in prenatal diagnosis is the identification of the pericallosal artery on color Doppler, which is visualized to follow the anterior part of the CC closely. However, the pericallosal artery loses its normal course in cases of partial CC agenesis and is absent at its posterior part ${ }^{26}$ (Fig. 6).

Associated brain anomalies include various malformations that may be diagnosed prenatally, such as Dandy-Walker malformation, interhemispheric cyst, porencephalic cyst, and lissencephaly, as well as other malformations that are difficult to correctly diagnose with prenatal ultrasound, including nodular periventricular heterotopias and polymicrogyria.

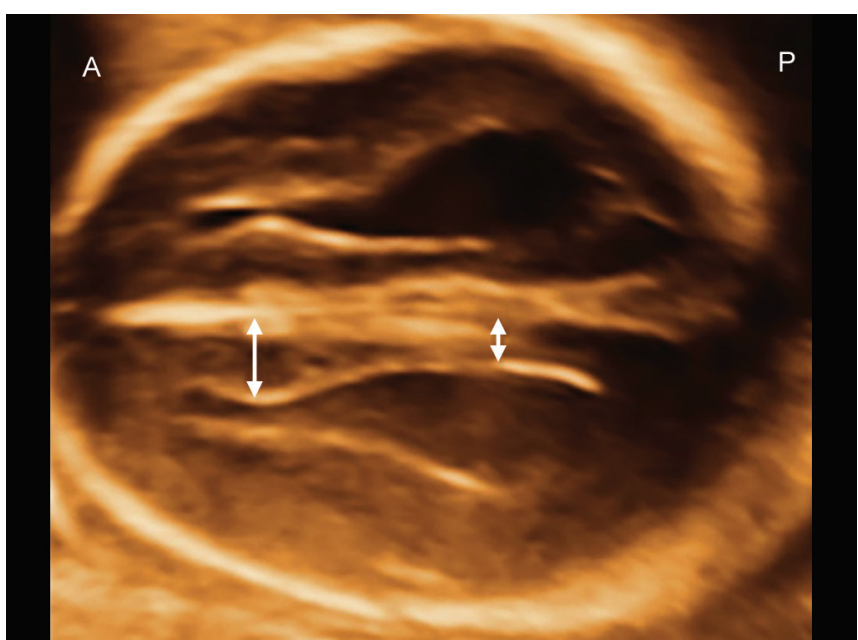

Fig. 4: Axial surface view of a fetus with ACC at 19 weeks' gestation. Tear drop shape of the lateral ventricles. The distance from the median plane to the inner border of the lateral ventricles is higher at the front side than in the posterior part of the ventricle $(\longleftrightarrow)$. A: Anterior; P: Posterior

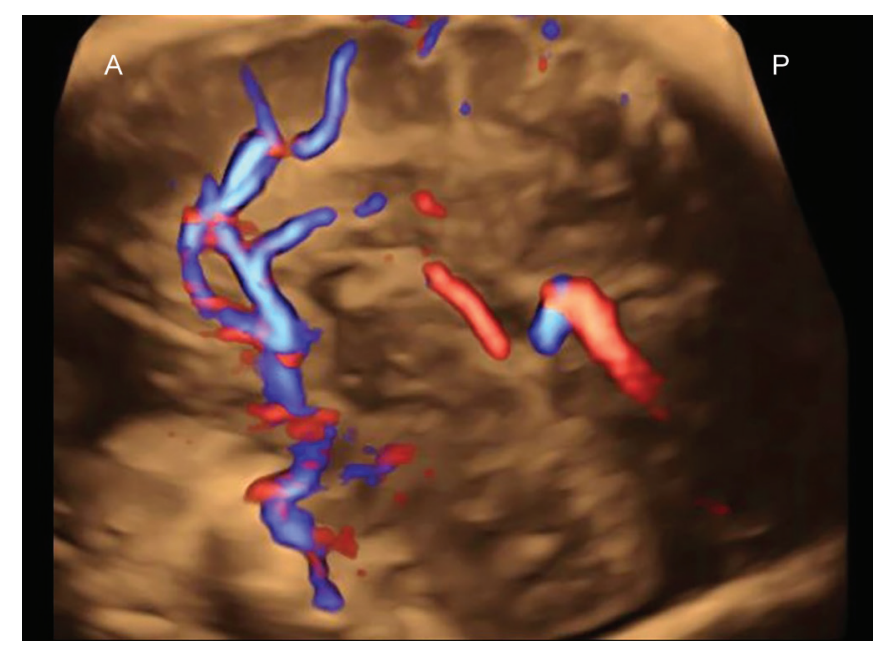

Fig. 6: Glass body mode of a fetal brain with partial ACC. The pericallosal artery shows a normal course in the anterior part, while the posterior part is absent. A: Anterior; P: Posterior

\section{HYPOPLASIA OF THE CORPUS CALLOSUM}

Hypoplasia of the corpus callosum is diagnosed when all anatomical segments are present and the height of at least one corpus callosum segment is less than the 5th percentile according to normal growth charts, independent of the length range ${ }^{6}$ (Fig. 7). Hypoplasia of the corpus callosum is classified as a secondary malformation due to an external factor affecting the number and size of corpus callosum axons. ${ }^{27}$ An association of hypoplasia of the corpus callosum with metabolic disorders such as amino acid metabolism disorders, mitochondrial disorders, and peroxisomal disorders has been reported prenatally ${ }^{28}$ and postnatally. ${ }^{6,29}$ Indirect signs of ACC are usually absent.

\section{THICKENING OF THE CORPUS CALLOSUM}

The presence of a thick corpus callosum has only rarely been reported in the literature. Hyperplasia is diagnosed 


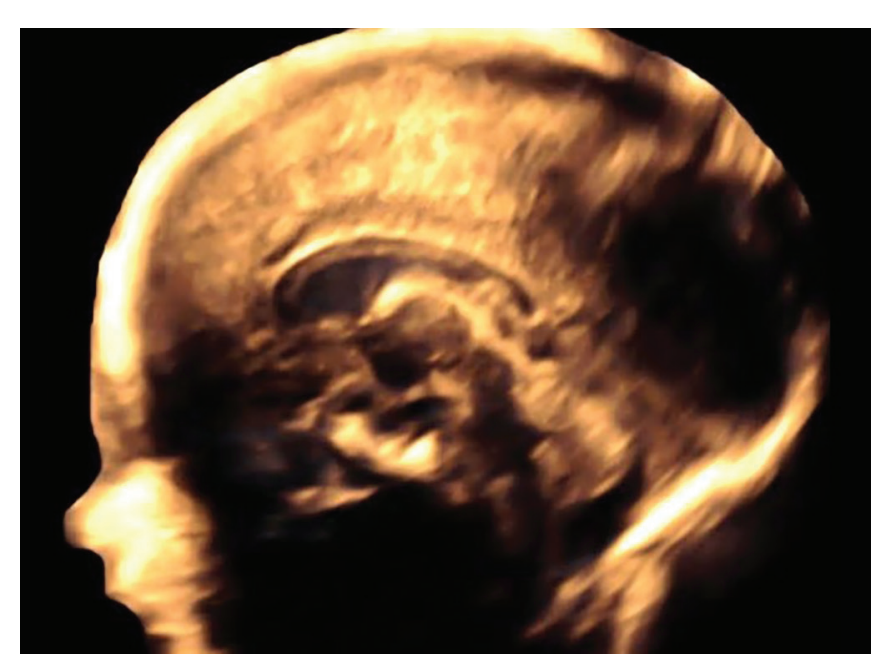

Fig. 7: Surface-rendered view of the sagittal plane in a case with hypoplasia of the corpus callosum at 28 weeks' gestation. The entire corpus callosum is present, but too thin for gestational age

when all anatomical segments are present and the height of at least one corpus callosum segment is found to range above the 95th percentile according to normal growth charts, while all three lengths are normal or lie outside of the normal range ${ }^{6}$ (Fig. 8). Corpus callosum hypertrophy has first been described in adults with schizophrenia. ${ }^{30} \mathrm{~A}$ thick corpus callosum may also be seen in patients with neurofibromatosis ${ }^{31}$ and in patients with macrocephalycapillary malformation syndrome. ${ }^{32}$

Microcephaly and a thick corpus callosum were diagnosed in 29 Finnish patients with Cohen syndrome, an autosomal recessive disorder. The clinical picture consists of nonprogressive psychomotor retardation, motor clumsiness and microcephaly, typical facial features, childhood hypotonia and hyperextensibility of the joints, ophthalmologic findings of retinochoroidal dystrophy, and myopia in patients over 5 years of age; and periods of isolated granulocytopenia. ${ }^{33}$

\section{COMBINATION OF HYPO- AND HYPERPLASIA OF THE CORPUS CALLOSUM}

A combination of hypo- and hyperplasia (= mixed abnormal thickening) of the corpus callosum is diagnosed when all anatomical segments are present and the height of at least one segment is found to range above the 95th percentile with an additional segment ranging below the 5 th percentile, independent of the length range $^{6}$ (Fig. 9). The described combination of hypo- and hyperplasia has been reported in association with both Apert syndrome and Goldenhar syndrome. ${ }^{6}$ The latter conditions represent the least frequently reported cases in the literature, which may be accounted for by the existing confusion in the definition of different corpus callosum pathologies.

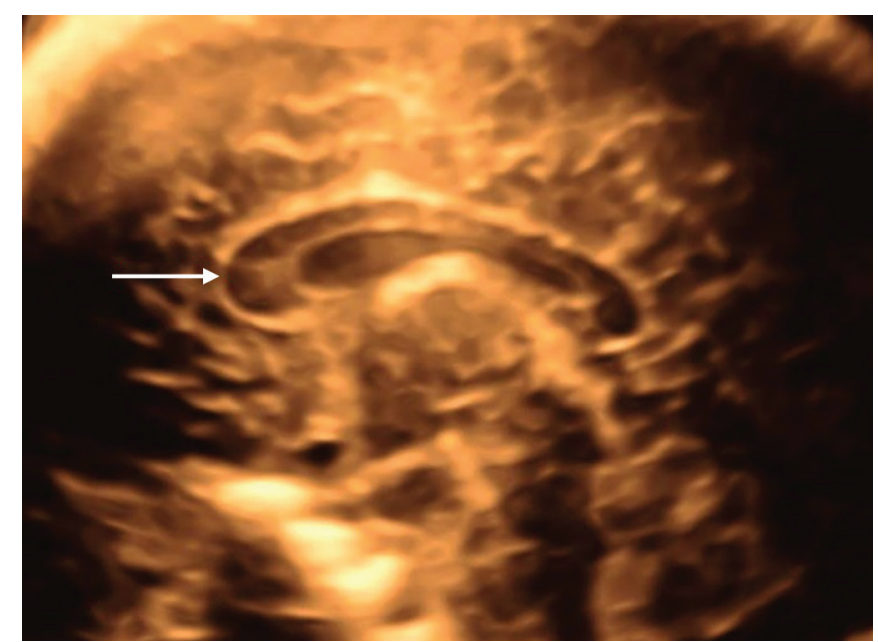

Fig. 8: Surface-rendered view of the sagittal plane in a case with hyperplasia of the corpus callosum (31 weeks' gestation). The genu $(\rightarrow)$ is much thicker than the other parts of the corpus callosum, which are in the normal range

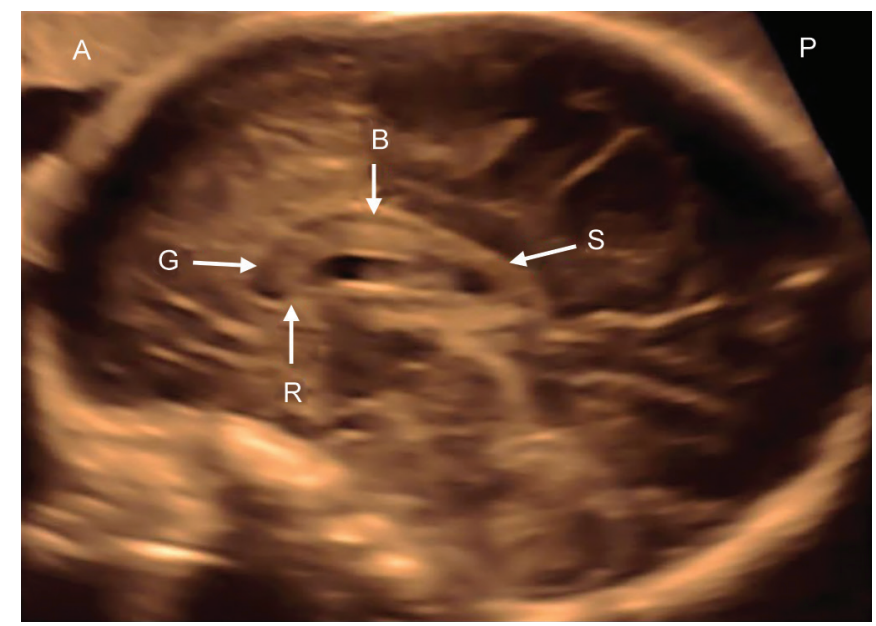

Fig. 9: Combination of hypo- and hyperplasia of the corpus callosum (29 weeks' gestation). Note the increased thickness of the rostrum $(R)$, genu $(G)$, and the anterior, while the posterior part of the body (B) and the splenium (S) are too thin for gestational age. A: Anterior; P: Posterior

\section{PERICALLOSAL LIPOMA}

Pericallosal lipoma associated with ACC was first described by Rokitansky. ${ }^{34}$ In prenatal ultrasound, this lesion can be demonstrated as a hyperechoic mass above the corpus callosum or at the expected location of the corpus callosum and may extend either toward the frontal lobe or toward the plexus choroideus ${ }^{6,35}$ (Fig. 10).

\section{SUMMARY}

Three-dimensional ultrasound offers the possibility of an exact demonstration of the corpus callosum as early as 18 weeks' gestation and enables a precise measurement at known anatomical regions, which allows the differentiation of possible anomalies of the fetal corpus callosum. Despite these advances, prognosis nevertheless continues to pose a challenge. 


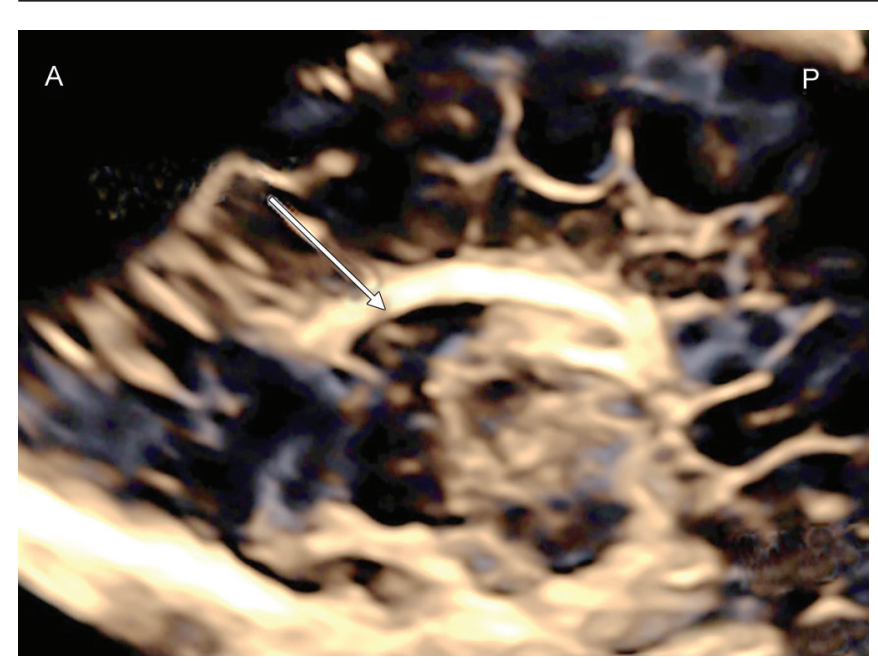

Fig. 10: Surface-rendered image of a lipoma of the corpus callosuma $(\rightarrow)$ at 38 weeks of gestation. Instead of a normal hypoechoic corpus callosum, a hyperechoic longitudinal mass is seen in the median plane. A: Anterior; P: Posterior

\section{REFERENCES}

1. Schoenemann PT, Sheehan MJ, Glotzer LD. Prefrontal white matter volume is disproportionately larger in humans than in other primates. Nat Neurosci 2005 Feb;8(2):242-252.

2. Tomasch J. Size, distribution, and number of fibres in the human corpus callosum. Anat Rec 1954 May;119(1):119-135.

3. Sperry, RW. Lateral specialization in the surgically separated hemispheres. In: Schmitt F, Worden F, editors. The neurosciences. Third study program. New York: Rockefeller University Press; 1974.

4. Gazzaniga MS. Forty-five years of spilt-brain research and still going strong. Nat Rev Neurosci 2005 Aug;6(8): 653-659.

5. Paul LK, Brown WS, Adolphs R, Tiszka JM, Richards LJ, Mukherjee P, Sheer EH. Agenesis of the corpus callosum: genetic, developmental and functional aspects of connectivity. Nat Rev Neurosci 2007 Apr;8(4):287-299.

6. Pashaj S, Merz E. Detection of fetal corpus callosum abnormalities by means of 3D ultrasound. Ultraschall Med 2016 Apr;37(2):185-194.

7. Freytag E, Lindenberg R. Neuropathologic findings in patients in a hospital for the mentally deficient: a survey of 359 cases. Johns Hopkins Med J 1967 Dec;121(6):379-392.

8. Grogono JL. Children with agenesis of the corpus callosum. Dev Med Child Neurol 1968 Oct;10(5):613-616.

9. Filly RA, Cardoza JD, Goldstein RB, Barkovich AJ. Detection of fetal central nervous system anomalies: a practical level of effort for routine sonogram. Radiology 1988 Aug;172(2): 403-408.

10. Comstock CH, Culp D, González J, Boal DB. Agenesis of the corpus callosum in the fetus: its evolution and significance. J Ultrasound Med. 1985 Nov;4(11):613-616.

11. Jeret JS, Serur D, Wisniewski K, Fisch C. Frequency of agenesi of the corpus callosum in the developmentally disabled population as determined by computerized tomography. Pediatr Neurosci 1985-1986;12(2):101-103.

12. Wang LW, Huang CC, Yeh TF. Major brain lesions detected on sonographic screening of apparently normal term neonates. Neuroradiology 2004 May;46(5):368-373.
13. Glass HC, Shaw GM, Ma C, Sherr EH. Agenesis of the corpus callosum in California 1983-2003: A population-based study. Am J Med Genetic A 2008 Oct;146A(19):2495-2500.

14. Girard N, Chaumoitre K, Confort-Gouny S, Viola A, Levrier O. Magnetic resonance imaging and the detection of the fetal brain anomalies, injury and physiologic adaptations. Curr Opin Obstet Gynecol 2006 May;18:164-176.

15. Merz E. Targeted depiction of the fetal corpus callosum with 3D-ultrasound. Ultraschall Med 2010 Oct;31(5):441.

16. Merz E. Current 3-D/4-D ultrasound technology in prenatal diagnosis. Eur Clin Obstet Gynaecol 2005 Dec;1(3);184-193.

17. Merz, E. 3-D Ultrasound in prenatal diagnosis. In: Merz E, editor. Ultrasound in obstetrics. Stuttgart (NY): Thieme; 2005.

18. Merz E, Benoit B, Blass GH, Baba K, Kratochwil A, Nelson T, Pretorius D, Jurkovic S, Chang MF, Lee A; ISUOG 3D Focus Group. Standardization of three-dimensional images in obstetrics and gynecology: consensus statement. Ultrasound Obstet Gynecol 2007 Jun;29(6):697-703.

19. Merz E. Tomographic ultrasound imaging. Ultraschall Med 2006 Aug;27(4):307-308.

20. Merz, E. 3-D ultrasound in obstetrics and gynecology. Philadelphia (PA): Lippincott Williams and Wilkins; 1998.

21. Pashaj S, Merz E, Wellek S. Biometric measurements of the fetal corpus callosum by three-dimensional ultrasound. Ultrasound Obstet Gynecol 2013 Dec;42(6):691-698.

22. Moutard ML, Kieffer V, Feingold J, Kieffer F, Lewin F, Adamsbaum C, Gélot A, Campistol I Plana J, van Bogaert P, André $\mathrm{M}$, et al. Agenesis of corpus callosum: prenatal diagnosis and prognosis. Childs Nerv Syst 2003 Aug;19(7-8):471-476.

23. Pilu G, Sandri F, Perolo A, Pittalis G, Grisolia G, Cocchi G, Foschini MP, Salvioli GP, Bovicelli L. Sonography of fetal agenesis of the corpus callosum: a survey of 35 cases. Ultrasound Obstet Gynecol 1993 Sep;3(5):318-329.

24. D'Addario V, Pinto V, Di Cagno L, Pintucci A. The midsagittal view of the fetal brain: a useful landmark in recognizing the cause of fetal cerebral ventriculomegaly. J Perinat Med 2005 Oct;33(5):423-427.

25. Oh, KY. Absent cavum septi pellucidi. In: Woodward $\mathrm{P}$, Kennedy A, Sohaey R, Byrne J, Oh K, Puchalski M, editors. Diagnostic imaging: obstetrics. Vol. 2. Salt Lake City (UT): Amirsys; 2006. pp. 54-55.

26. Volpe P, Paladini D, Resta M, Stanziano A, Salvatores M, Quarantellis M, De Robertis V, Buonadonna AL, Caruso G, Gentile M. Characteristics, associations and outcome of partial agenesis of the corpus callosum in the fetus. Ultrasound Obstet Gynecol 2006 May;27(5):509-516.

27. Ghi T, Carletti E, Contro E, Cera E, Falco P, Tagliavini G, Michelacci L, Tani G, Youssef A, Bonasoni P, et al. Prenatal diagnosis and outcome of partial agenesis and hypoplasia of the corpus callosum. Ultrasound Obstet Gynecol 2010 Jan;35(1):35-41.

28. Paupe A, Bidat L, Sonigo P, Lenclen R, Molho M, Ville Y. Prenatal diagnosis of hypoplasia of the corpus callosum in association with non-ketotic hyperglycinemia. Ultrasound Obstet Gynecol 2002 Dec;20(6):616-619.

29. Press GA, Barshop BA, Haas RH, Nyhan WL, Glass RF, Hesselink JR. Abnormalities of the brain in nonketotic hyperglycinemia. Am J Neuroradiol 1989 Mar-Apr;10(2):315-321.

30. Nasrallah NA, Andreasen NC, Coffman JA, Olson SC, Dunn VD, Ehrhardt JC, Chapman SC. Controlled magnetic resonance imaging study of corpus callosum thickness in schizophrenia. Biol Psychiatry 1986 Mar;21(3):274-282. 
31. Margariti PN, Blekas K, Katzioti FG, Zikou AK, Tzoufi M, Argyropoulou MI. Magnetization transfer ratio and volumetric analysis of the brain in macrocephalic patients with neurofibromatosis type 1. Eur Radiol 2007 Feb;17(2):433-438.

32. Conway RL, Pressman BD, Dobyns WB, Danielpour M, Lee J, Sanchez-Lara PA, Butler MG, Zackai E, Campbell L, Saitta SC, et al. Neuroimaging findings in macrocephaly-capillary malformation: a longitudinal study of 17 patients. Am J Med Genet A 2007 Dec;143A(24):2981-3008.
33. Kivitie-Kallio S, Norio R. Cohen syndrome: essential features, natural history, and heterogeneity. Am J Med Genet 2001 Aug;102(2):125-135.

34. Rokitansky, C. Lehrbuch der pathologischen anatomie. Vol. 2. Vienna: Braumuller; 1856. p. 33.

35. Ickowitz V, Eurin D, Rypens F, Sonigo P, Simon I, David P, Brunelle F, Avni FE. Prenatal diagnosis and postnatal followup of pericallosal lipoma: report of seven new cases. AJNR Am J Neuroradiol 2001 Apr;22(4):767-772. 